\title{
Observing and Modeling the Pacific Ocean [Video]
}

Libe Washburn ${ }^{\text {a }}$

Keywords: ocean observing systems, oceanographic radar, interdisciplinary oceanography, oceanic robotic vehicles, coastal oceanography https://doi.org/10.1525/001c.22189

Marine scientists incorporate a wide array of observations and models to understand the oceans, their dynamics, and the life they support. The development of new sensing technologies such as satellites, gliders, and robotic floats, as well as increasing public interest and funding for projects to investigate the ocean's role in climate change, has transformed marine sciences into "big data" sciences. But the observational scientist still faces numerous obstacles in measuring ocean characteristics such as sea surface height, currents, temperature, salinity, water color, ocean chemistry, and undersea life: electromagnetic radiation does not readily penetrate its waters, which makes it harder to conduct observations and communicate with underwater instruments, and because oceans are full of life, so called "biofouling" is a challenge to observing, especially in the sun-lit layers near the surface. Nevertheless, new technologies such as robotic vehicles and new sensors are enabling observations throughout the ocean water column. These technologies, coupled with rapidly advancing ocean models, are revolutionizing our understanding of the marine biosphere. [Image: UCSB undergraduates Andie Rupprecht and Sean Jawetz recover a robotic stand-up paddle board used for measuring ocean currents. Photograph by Libe Washburn.]

Video available: $\underline{\text { https://vimeo.com/527397347 }}$

\footnotetext{
a Libe Washburn is an oceanographer and research professor at the University of California, Santa Barbara in the Marine Science Institute and the Department of Geography. His current research focuses on how ocean circulation processes affect marine communities in near-shore ecosystems. Current projects include studies of: (1) coastal ocean dynamics, (2) circulation effects on phytoplankton blooms; 3) coastal current patterns and transport of marine organisms; and (5) exchange of water-borne materials between kelp forests and the offshore ocean. Washburn's research is based on observations from a variety of approaches including high frequency radar systems for mapping surface currents, moorings, ocean gliders, and other autonomous vehicles. He serves as the chair of the Board of Governors of the Southern California Coastal Ocean Observing System. Early in his career before entering to graduate school he worked as an aerospace engineer.
} 


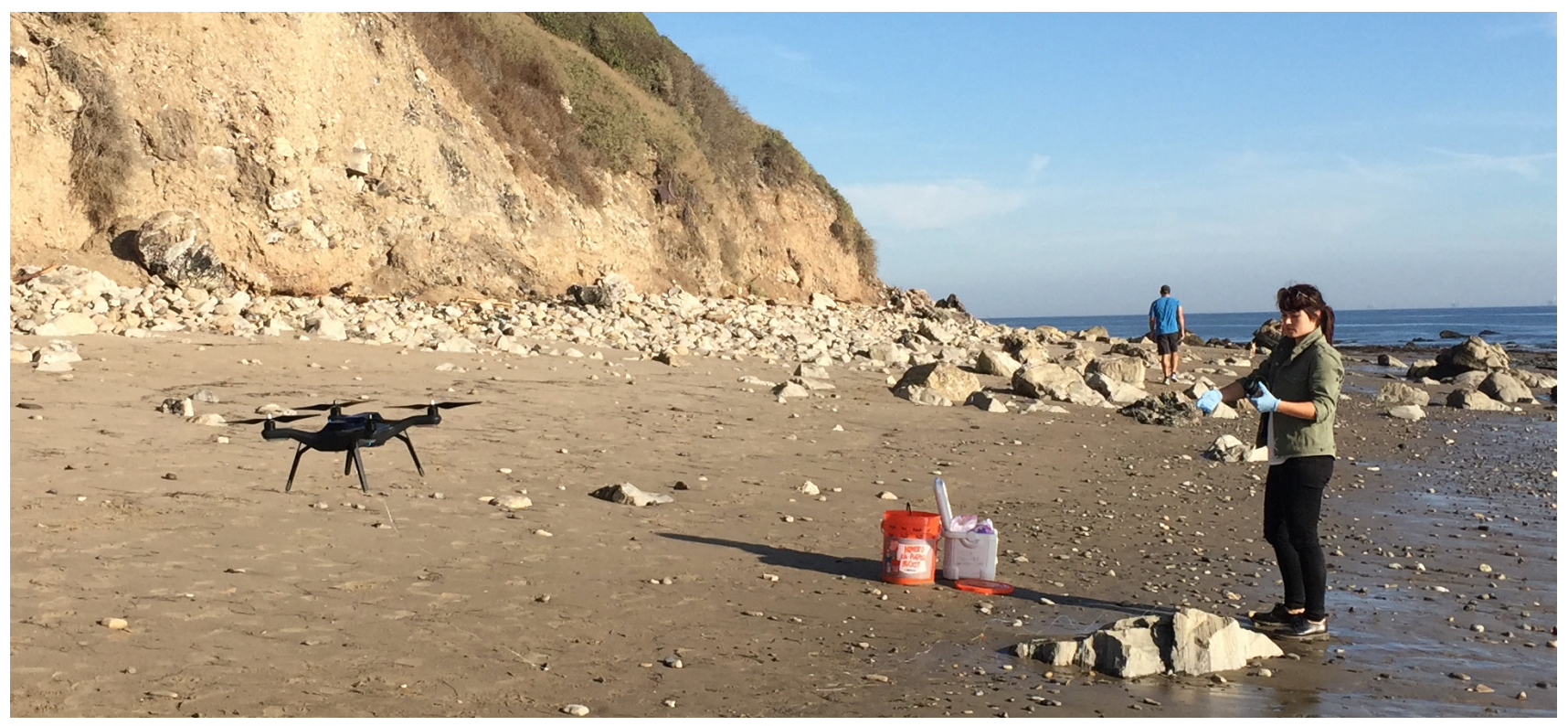

Figure 1: Graduate student Zoe Welch recovers a sampling bottle used for $\mathrm{pH}$ measurements in the coastal ocean. The bottle sample was collected by the drone in the foreground that is about to land. 